\title{
Indian Council of Medical Research consensus document for the management of buccal mucosa cancer
}

\author{
Goura Kishor Rath, \\ Purvish M Parikh ${ }^{l}$, \\ Shelley Hukku', \\ Balakrishnan Rajan", \\ Sandeep Kumar', \\ Hemant Malhotra ${ }^{5}$, \\ Seenu Vuthaluru', \\ Daya Nand Sharma, \\ Amish Vora ${ }^{7}$, \\ Deepak Kumar Shukla , \\ Tanvir Kaur ${ }^{8}$, \\ Ajeet Kumar Gandhi
}

Department of Radiation Oncology, All India Institute of Medical Sciences, New Delhi, ${ }^{1}$ Department of Medical

Oncology, Precision Medicine and Clinical Research, Asian Institute of Oncology, Somaiya Hospital, Mumbai, ${ }^{2}$ Department of Radiation Oncology BLK Super Speciality Hospital, New Delhi, ${ }^{3}$ Department of Radiation Oncology, Regional Cancer Centre, Trivandrum, Kerala, ${ }^{4}$ Department of Surgery, All India Institute of Medical Sciences, Bhopal, ${ }^{5}$ Division of Medical Oncology, Department of Medicine, RK Birla Cancer Center, SMS Medical College Hospital, Jaipur, ${ }^{6}$ Department of Surgery, All India Institute of Medical Sciences, New Delhi, ${ }^{7}$ Department of Medical Oncology, Max Super Speciality Hospital, Saket, New Delhi, ${ }^{8}$ Indian Council of Medical Research, New Delhi, India

Address for correspondence: Prof. Goura Kishor Rath, MD, Professor, Radiation Oncology, Chief, DRBRAIRCH, Head, NCl, All India Institute of Medical Sciences, New Delhi - 110029, India Tel: 011-26594673; Fax: 011-26589821 E-mail: gkrath2006@gmail.com

\section{EXECUTIVE SUMMARY}

- The document is based on consensus among the experts and best available evidence pertaining to Indian population and is meant for practice in India.

- Evaluation of a patient with newly diagnosed buccal mucosa cancer should include essential tests: Biopsy of the primary lesion, complete blood counts, renal function tests and liver function tests, chest X-ray, dental evaluation, and ultrasonogram (USG) of the neck in patients with no clinically enlarged neck nodes. Computed tomography (CT) magnetic resonance imaging (MRI)/positron emission tomography (PET)-CT are not recommended for all patients.

- For early stage disease (I/II), single modality treatment with surgery (with or without postoperative radiotherapy (PORT) or radiotherapy (RT) (brachytherapy or external beam radiotherapy [EBRT] or in combination) is recommended.

- For locally advanced Stage (III-IV A), surgery followed by RT with or without chemotherapy, concurrent chemo-RT, altered fractionation RT schedules, induction chemotherapy, followed by surgery with or without RT are valid treatment options.

- Stage IV B/metastatic diseases are treated with intent of palliation with chemotherapy and/or RT along with best supportive care.

- Clinical examination including history and physical examination is done at each follow-up visit and no routine radiological investigation is recommended.

\section{INCIDENCE}

Carcinoma of the buccal mucosa (BMC) is the commonest cancer of the oral cavity in India. As per population based cancer registry data ${ }^{[1]}$ of the National Cancer Registry Program, of the Indian Council of Medical Research, the males of Ahmedabad urban showed highest age adjusted rate (AAR) for mouth cancer (17.1) followed by Bhopal (12.5). For females however, Kamrup urban district (7.6) and East Khasi Hills of Meghalya (7.3) showed the highest AAR, followed by Bangalore (6.2). In the hospital-based cancer registry ${ }^{[2]}$ report, cancer of the oral cavity is also ranked as the leading site in Mumbai in males and was within the first five leading sites in all registries in males. In the developed countries, BMC is relatively uncommon when compared to the Indian subcontinent. ${ }^{[3]}$ As per the recent GLOBOCAN 2012, 77,000 new cases of oral cavity cancers are diagnosed every year in India and 52,000 die of this disease. ${ }^{[4]}$ The high incidence of BMC in our country is attributable to the extensive use of tobacco in various forms and the locally advanced cancers account for about $70 \%$ of the cases at the time of presentation.

\section{PURPOSE}

DOI:

$10.4103 / 0971-5851.138953$
Several international consensus guidelines are available for the management of oral cavity cancers, but none of 
them addresses BMC in particular. Therefore, formulating reliable guidelines based on western data for Indian patients is questionable given the fact that buccal mucosa tumors are quite rare in the developed countries. There is obviously an urgent need to formulate consensus statement for the management of BMC based on Indian data ${ }^{[5-9]}$ and experience which would not only incorporate the evidence available but would also be feasible to be practiced in the hospitals of India. Oral cancer in India is different compared to the western countries. Here, it involves the gingivo buccal sulcus (the site where the tobacco quid is commonly kept by the patient). The nature of spread, biological behavior and the treatment is also different. Based on the available evidence and expert consensus opinion, we present the proposed national consensus document for management of BMC.

\section{DIAGNOSIS}

Evaluation of a patient presenting with a lesion in the buccal mucosa should be aimed at pathological confirmation and staging of the disease. Essential test, which needs to be done in all patients include: Biopsy of the primary lesion, complete blood counts, renal function tests and liver function tests, chest X-ray, USG of the neck in patients with no clinically enlarged neck nodes, dental evaluation and CT scan except in patients with early lesions and clinically USG proven no lymphadenopathy in the neck. CT scan/MRI is advisable if mandible is involved clinically and orthopantomogram is negative, lesion is involving the retromolar trigone, there is suspected involvement of pterygoids or pterygoid plate, lesion is extending into the upper gingivo buccal sulcus and there is suspicious involvement of paranasal sinuses or if there is need to assess the operability of cervical lymph nodes. Evaluation under anesthesia should be done in cases where clinical examination is not feasible. $2-\left[{ }^{18} \mathrm{~F}\right]$ fluoro-2-deoxy-D-glucose PET (PET-CT) is not routinely recommended.

Extensive investigations are not recommended in cases with (intent of treatment in these cases is primarily palliation) hard and fixed N3 nodes, extensive skin involvement with or without cutaneous nodules, severe trismus not due to oral submucous fibrosis or clinical involvement of infra temporal fossa.

Staging should be done with American Joint Committee on Cancer staging manual ${ }^{[10]}\left(7^{\text {th }}\right.$ edition, 2009) and patients should be assigned a TNM and a group stage (which would remain unchanged throughout).

\section{TREATMENT PLAN}

Treatment decisions are based on the stage. The aim of treatment is "curative" for patients with Stage I-IV A and "palliative" for patients with Stage IV B (locoregionally advanced disease) and IV C (metastatic disease).

\section{Early Stage (I/II)}

For early Stage (I or II), single modality treatment is used: Either surgery or RT alone.

Wide local excision and supra-omohyoid neck dissection (SOND) should be the surgical procedure of choice. SOND may be avoided if the patient is highly compliant and meets all the criteria: T1 lesion, node negative status proven by USG, histologically well differentiated lesions and thickness of infiltration ${ }^{[11]}$ is $<4 \mathrm{~mm}$. All patients with close/positive margin should be considered for re-excision. If the patient is not a candidate for the same, PORT should be considered. Multiple node positivity, margin positive disease and presence of extra-capsular spread ${ }^{[12,13]}$ mandate the use concurrent chemo-radiation. The minimum required PORT dose is $60 \mathrm{~Gy}$ at 1.8-2 Gy/fraction. This may be delivered in a phased manner. The initial phase would deliver $44 \mathrm{~Gy}$ in 22 fractions over $4 \frac{1}{2}$ weeks to the primary and nodal areas using conventional treatment planning, three-dimensional conformal radiotherapy (3D-CRT) or intensity modulated radiotherapy (IMRT). ${ }^{[14]}$ Every effort should be made to spare the contralateral parotids. In the second phase the spinal cord should be shielded and dose delivered to receive a minimum of 60 Gy. In presence of margin positive disease or extra-capsular spread $66 \mathrm{~Gy}$ is the recommended dose. This may be achieved using electrons or photon boost.

Interstitial brachytherapy alone is used in highly compliant individuals of early buccal mucosa cancers with all of the following tumor characteristics: Early lesions preferably $<2 \mathrm{~cm}$, accessible lesions, histologically well differentiated lesions, lesions situated well away from the bone, node negative status proven by USG. Brachytherapy may be delivered using low dose rate ${ }^{[15]}(\mathrm{LDR})$ or high dose rate (HDR) systems. In general, dose prescription encompasses the primary with $1.0-1.5 \mathrm{~cm}$ margins. The regional nodes are not addressed at this time of treatment. Doses for LDR are 65-70 Gy over 6-7 days and for HDR is $48 \mathrm{~Gy}$ in 12 fractions (4 Gy twice a day over 6 days).

Patients who are not suitable for brachytherapy may be treated with EBRT. EBRT is delivered using conventional planning/3D-CRT/IMRT to doses of 66-70 Gy at 1.8-2 Gy/fraction over 7-8 weeks (or a biologically equivalent dose) with adequate margins all around the lesion and including Level I and II nodes. Neck needs to be observed through close follow-up. In conventional RT planning, initial lateral portals are treated to $44 \mathrm{~Gy}$ in 22 fractions/over 4.5 weeks, followed by 12-16 Gy after 
spine shielding. Dose of EBRT is restricted to 45-50 Gy if interstitial boost (dose of 20-25 Gy [LDR] or equivalent [HDR]) is given.

When concurrent chemo-radiation is used, cisplatin is the preferred agent. ${ }^{[16]}$ Weekly cisplatin $30-40 \mathrm{mg} / \mathrm{m}^{2}$ should be used with minimum cumulative dose of $200 \mathrm{mg} / \mathrm{m}^{2}$. Three weekly regimen of cisplatin with dose of $100 \mathrm{mg} / \mathrm{m}^{2}$ (on day 1, 22, and 43 of RT) can be used. Monoclonal antibody therapy directed against epidermal growth factor receptor (cetuximab and nimotuzumab) added to radiation therapy improves outcome, however, there is limited evidence in the Indian literature ${ }^{[17]}$ and cost benefit ratio may be considered before taking a decision. In patients who are not candidates for cisplatin, carboplatin and paclitaxel is the regime of choice for chemo-radiation. Feeding through nasogastric tube, gastrostomy or jejunostomy is strongly recommended during chemo-radiation.

\section{Locally advanced (Stage III-IV A)}

Patients should be offered combined modality treatment for these disease stages. Treatment options include: Surgery, followed by RT with or without chemotherapy, concurrent chemo-RT, altered fractionation RT schedules, induction chemotherapy, followed by surgery with or without RT.

Surgical aim should be to widely excise the tumor to obtain negative margins $(0.5-1 \mathrm{~cm})$ all around. Modified radical neck dissection (MND) should be the procedure of choice. Extended SOND is followed by MND if matted lymph nodes or extensive cervical lymph nodes involvement is found peroperatively and if nodes are positive on frozen section. Segmental mandibulectomy should be avoided just to facilitate access to primary cancers of oral cavity. However, it can be done in cases where there is: Gross invasion of mandible by tumor, proximity of oral commissure to the mandible in a previously irradiated patient, invasion of inferior alveolar nerve or canal by cancer or massive soft tissue disease is present adjacent to the mandible.

Principles of radiation and concurrent chemo-radiation remain the same as in early stage disease. Altered fractionation schedules are valid option for patients who are not candidates for surgery or are unsuitable for chemo-radiation. ${ }^{[18]}$

For borderline inoperable disease, chemotherapy may be considered to facilitate better resection. Based on recent evidences in the literature, ${ }^{[19]}$ combination regimen with cisplatin, 5-flurouracil and taxane is considered the most effective neoadjuvant regimen. Alternative chemotherapy schedule is cisplatin plus 5-flurouracil. ${ }^{[20]}$ Both chemotherapy regimens have Level I evidence ${ }^{[1,20]}$ in terms of their efficacy in neoadjuvant setting in head and neck cancers. Resectability subsequent to induction chemotherapy is best assessed by clinical evaluation and imaging where indicated. CT or MRI scan (if available) may be used for assessment of disease in inaccessible areas such as pterygopalatine fossa or infratemporal fossa. It is also preferable that the pre- and post-chemotherapy assessments are performed by the same group of oncologists. Patients who have progressive disease after 3-4 cycles of induction chemotherapy should be considered for palliative treatment only.

\section{Advanced Stage IV B/metastatic disease}

Aim of treatment in these patients is palliation with maintenance of quality of life. If the primary with or without nodal disease is symptomatic, consideration should be given to palliative ${ }^{[21]}$ EBRT. Doses of $30 \mathrm{~Gy}$ in 10 fractions over 2 weeks or weekly EBRT of 7-8 Gy/fraction/week for 2-3 weeks may be employed. Systemic disease or progressive local disease after RT could be treated with chemotherapy with any of the following regimens: Single agent methotrexate, single agent cisplatin, cisplatin plus 5-flurouracil, cisplatin plus paclitaxel, cisplatin plus docetaxel or cisplatin plus cetuximab. ${ }^{[2]}$

\section{RECURRENT DISEASE}

For recurrent disease, if recurrence is operable and patient is RT naïve, surgery followed by PORT with or without chemotherapy or radical RT (for recurrent T1/T2) may be employed. Concurrent chemo-radiation or radiation alone is a valid option in these patients, if surgery is not medically feasible or patient is not willing for surgery.

If surgery is not feasible and patient has poor performance status the treatment should be individualized. If RT naïve, palliative RT else palliative chemotherapy may be employed along with best supportive care.

\section{FOLLOW-UP AND REHABILITATION}

Patient should be encouraged to maintain abstinence from tobacco and alcohol and maintain oral hygiene. Dental prophylaxis, shoulder exercises, jaw stretching exercises, swallowing and speech rehabilitation should be instituted as appropriate. The aim of follow-up is to assess the recurrence in primary and nodal areas, to rule out any second primary and to assess any complication due to surgery/RT. Follow-up is done every $2-3$ months for first 2 years, six monthly for next 3 years and annually thereafter. Clinical examination, including history and physical examination is done at each visit and no routine radiological investigation is recommended.

\section{REFERENCES}

1. National Cancer Registry Programme, Indian Council of 
Medical Research: Three year report of population based cancer registries 2009-2011. Available from: Http://www. pbcrindia.org/. [Last accessed on 2014 Jun 16].

2. National Cancer Registry Programme, Indian Council of Medical Research: Consolidated report of Hospital Based Registries 2007-2011. Available from: Http://www. hbcrindia.org/. [Last accessed on 2014 Jun 16].

3. Ferlay J, Shin HR, Bray F, Forman D, Mathers C, Parkin DM. Estimates of worldwide burden of cancer in 2008: GLOBOCAN 2008. Int J Cancer 2010;127:2893-917.

4. GLOBOCAN 2012: Estimated cancer incidence, prevalence and mortality worldwide in 2012. http://www.globocan. iarc.fr/Pages/fact_sheets_population.aspx. [Last accessed on 2014 Jun 16].

5. Krishnamurthi S, Shanta V, Sastri DV. Combined therapy in buccal mucosal cancers. Radiology 1971;99:409-15.

6. Bahadur S, Kumar S, Tandon DA, Rath GK, De S. Combined therapy in advanced head and neck cancers. J Laryngol Otol 1992;106:412-5.

7. Iype EM, Pandey M, Mathew A, Thomas G, Sebastian P, Nair MK. Oral cancer among patients under the age of 35 years. J Postgrad Med 2001;47:171-6.

8. Badakh DK, Grover AH. The efficacy of postoperative radiation therapy in patients with carcinoma of the buccal mucosa and lower alveolus with positive surgical margins. Indian J Cancer 2005;42:51-6.

9. Yeole BB, Ramanakumar AV, Sankaranarayanan R. Survival from oral cancer in Mumbai (Bombay), India. Cancer Causes Control 2003;14:945-52.

10. Edge SB, Byrd DR, Compton CC, Fritz AG, Greene FL, Trotti A, editors. AJCC Cancer Staging Manual. $7^{\text {th }}$ ed. New York, NY: Springer; 2010.

11. Mishra RC, Parida G, Mishra TK, Mohanty S. Tumour thickness and relationship to locoregional failure in cancer of the buccal mucosa. Eur J Surg Oncol 1999;25:186-9.

12. Cooper JS, Pajak TF, Forastiere AA, Jacobs J, Campbell BH, Saxman SB, et al. Postoperative concurrent radiotherapy and chemotherapy for high-risk squamous-cell carcinoma of the head and neck. N Engl J Med 2004;350:1937-44.

13. Bernier J, Domenge C, Ozsahin M, Matuszewska K, Lefèbvre JL, Greiner RH, et al. Postoperative irradiation with or without concomitant chemotherapy for locally advanced head and neck cancer. N Engl J Med 2004;350:1945-52.

14. Pederson AW, Salama JK, Witt ME, Stenson KM,
Blair EA, Vokes EE, et al. Concurrent chemotherapy and intensity-modulated radiotherapy for organ preservation of locoregionally advanced oral cavity cancer. Am J Clin Oncol 2011;34:356-61.

15. Tayier A, Hayashi K, Yoshimura R. Low-dose-rate interstitial brachytherapy preserves good quality of life in buccal mucosa cancer patients. J Radiat Res 2011;52:655-9.

16. Pignon JP, le Maître A, Maillard E, Bourhis J, MACH-NC Collaborative Group. Meta-analysis of chemotherapy in head and neck cancer (MACH-NC): An update on 93 randomised trials and 17,346 patients. Radiother Oncol 2009;92:4-14.

17. Dattatreya S, Goswami C. Cetuximab plus radiotherapy in patients with unresectable locally advanced squamous cell carcinoma of head and neck region - a open labelled single arm phase II study. Indian J Cancer 2011;48:154-7.

18. Bourhis J, Overgaard J, Audry H, Ang KK, Saunders M, Bernier $\mathrm{J}$, et al. Hyperfractionated or accelerated radiotherapy in head and neck cancer: A meta-analysis. Lancet 2006;368:843-54.

19. Vermorken JB, Remenar E, van Herpen C, Gorlia T, Mesia R, Degardin $\mathrm{M}$, et al. Cisplatin, fluorouracil, and docetaxel in unresectable head and neck cancer. $N$ Engl $J$ Med 2007:357:1695-704.

20. Posner MR, Hershock DM, Blajman CR, Mickiewicz E, Winquist E, Gorbounova V, et al. Cisplatin and fluorouracil alone or with docetaxel in head and neck cancer. N Engl J Med 2007;357:1705-15.

21. Agarwal JP, Nemade B, Murthy V, Ghosh-Laskar S, Budrukkar A, Gupta T, et al. Hypofractionated, palliative radiotherapy for advanced head and neck cancer. Radiother Oncol 2008;89:51-6.

22. Vermorken JB, Trigo J, Hitt R, Koralewski P, Diaz-Rubio E, Rolland $\mathrm{F}$, et al. Open-label, uncontrolled, multicenter phase II study to evaluate the efficacy and toxicity of cetuximab as a single agent in patients with recurrent and/or metastatic squamous cell carcinoma of the head and neck who failed to respond to platinum-based therapy. J Clin Oncol 2007;25:2171-7.

How to cite this article: Rath GK, Parikh PM, Hukku S, Rajan B, Kumar S, Malhotra $\mathrm{H}$, et al. Indian Council of Medical Research consensus document for the management of buccal mucosa cancer. Indian J Med Paediatr Oncol 2014;35:136-9.

Source of Support: Nil, Conflict of Interest: None declared.

\section{LATE DR KALLA VENKAT ANAND YOUNG RESEARCHER AWARD}

ISMPO is now inviting abstracts for the first 'Late Dr Kalla Venkat Anand Young Researcher Award'. The award honours a young medical oncologist from India (age $\leq 40$ years as on 31.12.2014) whose research work is adjudged to be the best among those submitted for the Annual ISMPO Meeting to be held in Kolkata on 26 - 28 December, 2014. The Awardee will be conferred a Medal along with a grant. For detailed information please visit www.ismpo.org. Last date of abstract submission is 30.10.2014 (Midnight). 